\title{
impacto da Lei de Responsabilidade Fiscal: uma análise do desempenho das contas públicas municipais do Estado do Rio Grande do Sul
}

Ari Söthe; Vilson Söthe y Clésia Ana Gubiani

\section{Introdução}

A Lei Complementar no 101/2000, Lei de Responsabilidade Fiscal (LRF), fundamenta-se na responsabilidade com o dinheiro público. Assim, a lei trouxe uma série de novos desafios aos gestores públicos brasileiros. Entre os princípios da lei estão o planejamento, a transparência em relação aos gastos, o controle e a participação da sociedade.

Existe uma diferença da LRF em relação às demais leis do setor público: a de responsabilizar a área de gestão financeira dos órgãos e poderes públicos a partir de um acompanhamento sistemático de desempenho da administração pública. O descontrole com o dinheiro público resultava em desvio e gasto ineficiente. Dessa forma, a LRF trouxe em seus artigos diversas obrigações a serem cumpridas pelos gestores, definidos como responsáveis pelo dinheiro público.

Estudos anteriormente desenvolvidos sobre a LRF, tratando da sua eficácia e do seu impacto na gestão pública municipal, mostram avanços importantes na 
gestão dos recursos públicos e no cumprimento dos princípios norteadores da lei. Dentro desse enfoque, Santos (2009) realizou estudo sobre o impacto da LRF na arrecadação tributária dos municípios do Rio Grande do Sul. Fazendo uma análise do período de 1996 a 2005, observou que a arrecadação dos tributos de competência dos municípios aumentou expressivamente, principalmente a do Imposto Sobre Serviços.

Dentro da mesma linha de estudo, Moura Neto e Palombo (2006) desenvolveram uma pesquisa objetivando identificar os impactos da LRF e das transferências intergovernamentais sobre a arrecadação própria dos municípios brasileiros. Concluíram que a LRF gerou esforço tributário positivo na arrecadação própria, não compensando os efeitos negativos advindos do recebimento de recursos via transferências federais por parte dos municípios brasileiros.

Pereira e Silva (2009) analisaram até que ponto a promulgação da Lei de Responsabilidade Fiscal contribuiu para o aumento da aprovação de prestação de contas de prefeituras baianas. Para isso, os autores analisaram os tipos de decisão do Tribunal de Contas dos Municípios, do período de 1993 a 2006. Merece destaque em suas conclusões que a publicação da LRF em 2000 não resultou em diminuição do número de contas de prefeituras reprovadas, tendo em vista o caráter normatizador e sancionador da Lei.

O presente estudo diferencia-se dos anteriores, pois busca analisar os níveis de impacto da LRF na aprovação das contas públicas municipais do Estado do Rio Grande do Sul. Assim, elaborou-se a seguinte questão de pesquisa: Quais foram os impactos da Lei de Responsabilidade Fiscal nas contas públicas dos governos municipais do Estado do Rio Grande do Sul? Este estudo tem por objetivo analisar os impactos da Lei de Responsabilidade Fiscal nas contas públicas dos governos municipais do Estado do Rio Grande do Sul.

Para tanto, foram analisados os princípios norteadores da LRF, os seus principais objetivos e seu impacto no cenário das contas públicas dos municípios gaúchos. Realizou-se um estudo descritivo, com análise de conteúdo das informações disponibilizadas no sitio do Tribunal de Contas do Estado do Rio Grande do Sul. $\mathrm{Na}$ interpretação dos dados disponibilizados, foram avaliados e comparados os pareceres das contas de gestão fiscal dos exercícios de 2000 a 2008, os aspectos da lei analisados e as principais irregularidades cometidas pelos gestores, que resultaram na emissão de parecer pelo não atendimento da LRF.

Este estudo se justifica pela necessidade de avaliação da eficácia da LRF no âmbito municipal, considerando os objetivos da lei para a melhoria na gestão pública. Outro elemento relevante foi a identificação da postura dos gestores públicos municipais, quanto ao cumprimento dos princípios constitucionais e administrativos da ordem fiscal brasileira estabelecidos pela LRF.

O presente trabalho está organizado em cinco seções, tendo início com esta introdução. Em seguida, apresenta-se a fundamentação teórica que serviu de sustentação à pesquisa. Na sequência, apresentam-se os aspectos metodológicos utilizados para desenvolver a pesquisa. Logo após, faz-se a descrição, análise e interpretação dos dados coletados. Por último, apresentam-se as conclusões do estudo realizado e as recomendações para futuras pesquisas sobre o tema investigado. 


\section{Fundamentação teórica}

Neste capítulo são abordados os principais aspectos da Lei de Responsabilidade Fiscal, considerada um divisor de águas pela mudança que tem provocado no perfil da administração pública brasileira, e, por consequência, apontadas as alterações na forma de atuação dos tribunais de contas estaduais e municipais, no que se refere ao acompanhamento e controle do efetivo cumprimento desta lei.

\section{A Lei de Responsabilidade Fiscal}

A Lei Complementar no 101, de 04 de maio de 2000, mais conhecida como Lei de Responsabilidade Fiscal (LRF), estabelece normas de finanças públicas voltadas para a responsabilidade na gestão fiscal. Esta lei foi promulgada para regulamentar os artigos de número 163 a 169 do Capítulo II e Título VI das Finanças Públicas da Constituição Federal de 1988.

A responsabilidade fiscal pode ser traduzida como sendo o cuidado, o zelo na arrecadação das receitas e na realização das despesas públicas, obrigando-se o gestor a agir com transparência e de forma planejada. Destaca-se o seu aspecto inovador, conforme Nunes (2002, p. 88):

Reside no fato de responsabilizar o administrador público pela gestão financeira, criando mecanismos de acompanhamento sistemático (mensal, trimestral, anual e plurianual) do desempenho, evitando desvios de verbas, corrupção e roubos no orçamento público.

Por isso, a LRF busca comprometer o gestor público com uma política fiscal responsável. A atribuição de responsabilidades ao gestor foi consolidada a partir da publicação da Lei $n^{\circ} 10.028 / 2000$, chamada de Lei de Crimes. Cumpre ressaltar que esta lei alterou o Decreto-Lei $\mathrm{n}^{\circ}$ 2.848/1940 (Código Penal). Por sua vez, a Lei $\mathrm{n}^{\circ}$ 1.079/1950 define os crimes de responsabilidade e regula o respectivo processo de julgamento.

A sanção penal, nos termos da Lei de Crimes, recairá sobre o administrador público que não seguir as regras gerais da LRF. Dessa forma, o principal objetivo da

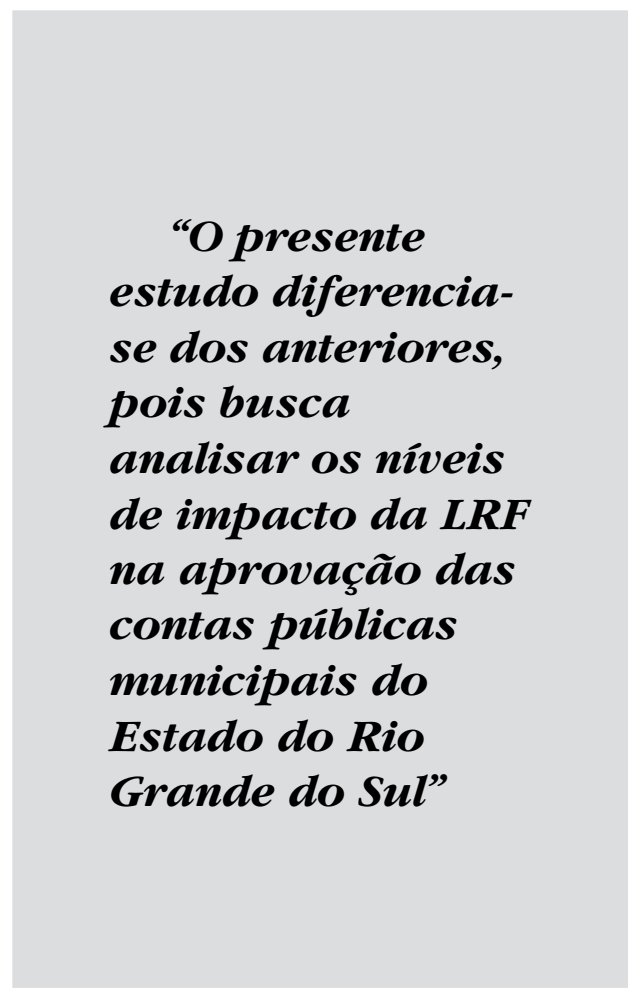

LRF está explicitado em seu Art. $1^{\circ}, \mathbb{} 1^{\circ}$, que assim dispõe:

Art. $1^{\circ}, \int 1^{\circ} \mathrm{A}$ responsabilidade na gestão fiscal pressupõe a ação planejada e transparente, em que se previnem riscos e corrigem desvios capazes de afetar o equilíbrio das contas públicas, mediante o cumprimento 
de metas de resultados entre receitas e despesas e a obediência a limites e condições no que tange a renúncia de receita, geração de despesas com pessoal, da seguridade social e outras, dívidas consolidada e mobiliária, operações de créditos, inclusive por antecipação de receita, concessão de garantia e inscrição em Restos a Pagar.

Denota-se que a LRF foi promulgada para melhorar a administração pública, por meio da busca de melhor qualidade da gestão fiscal e equilíbrio das finanças públicas. O maior beneficiário dessa lei é o cidadão, que passa a contar com transparência na administração e garantia de eficiente aplicação dos tributos pagos.

Nóbrega (2002) reforça que os objetivos da LRF buscam instituir uma gestão fiscal responsável; prevenir desvios e estabelecer mecanismos de correção; modificar profundamente o regime fiscal brasileiro, aumentando a transparência no setor público, com maior divulgação e entendimento das contas públicas. $\mathrm{O}$ alcance desses objetivos, segundo a LRF, está nos quatro princípios norteadores da administração pública, que são o planejamento, a transparência, o controle e a responsabilidade. Lopes e Slomski (2004) complementam que, pelo seu funcionamento como auditoria preventiva nos municípios, a LRF obriga os gestores a prestar contas ao Tribunal de Contas mensalmente.

Ao enfatizar o monitoramento da gestão fiscal, a LRF valorizou os instrumentos de planejamento governamental, compreendidos pelo Plano Plurianual (PPA), Lei de Diretrizes Orçamentárias (LDO) e Lei Orçamentária Anual (LOA), que são previstos na Constituição de 1988 como referências básicas do sistema orçamentário nacional e que deverão ser compatíveis e consistentes, portanto, orientadores das políticas públicas (SILVA, 200-).

Em relação à fiscalização da gestão fiscal, cabe ao Poder Legislativo, diretamente ou com o auxílio dos tribunais de contas, e ao sistema de controle interno examinar o cumprimento das disposições estabelecidas pela LRF. Como o controle interno, na prática, faz parte da estrutura da administração pública, a fiscalização fica efetivamente a cargo dos tribunais de contas, órgãos técnicos que auxiliam o Poder Legislativo no controle externo (SILVA, 200-).

A LRF estabeleceu nova abrangência para o controle externo a cargo dos tribunais de contas, que devem emitir pareceres prévios relativos às contas anuais dos chefes dos poderes Executivo, Legislativo, Judiciário e do Ministério Público. Além disso, submetem-se à sua apreciação os relatórios resumidos da execução orçamentária, emitidos bimestralmente, e os relatórios quadrimestrais e semestrais da gestão fiscal (SiLVA, 200-).

\section{A Lei de Responsabilidade Fiscal na gestão fiscal}

Instituída na era da administração pública marcada por governantes que administravam as contas públicas gastando mais do que arrecadavam, a Lei complementar no 101, de 04 de maio de 2000 (LRF), veio sanar importante lacuna para a obtenção do equilíbrio fiscal do país, ao estabelecer regras claras para a adequação de despesas públicas em níveis compatíveis com as receitas de cada ente da federação, envolvendo todos os poderes.

Oliveira (2002) reforça que a LRF deixa claro o seu propósito de corrigir os rumos da administração pública nos três níveis da Federação, limitando os gastos 
de acordo com as receitas, mediante planejamento, organização, controle interno, controle externo e transparência das ações de governo em relação à população. Acrescenta que os administradores públicos são expressamente responsáveis pelas ações implementadas no exercício de suas funções e sujeitos a penalidades definidas em legislação própria.

Nesse sentido, a LRF estabeleceu regras claras destinadas a assegurar a observância de parâmetros de sustentabilidade da política fiscal e boa governança. No Quadro 1 são apresentados de forma sintetizada os aspectos mais relevantes da lei em função da correta gestão pública.

Percebe-se que a gestão pública deverá ser levada além da austeridade fiscal, que passou a ser obrigatória, sob pena do descumprimento. A LRF direciona aos municípios um espírito inovador da gestão responsável, apoiada em quatro eixos para cumprir sua função de reguladora das finanças públicas: o planejamento, a transparência, o controle e a responsabilização.

No que se refere às punições, Khair (2001, p. 70) entende que "para que a lei torne-se efetiva, é preciso garantir a responsabilização efetiva e ágil de seus transgressores, sob pena de cair em descrédito". Nesse sentido, paralelamente às sanções institucionais, descritas no próprio texto da LRF, o seu descumprimento poderá representar para o administrador público a aplicação de sanções penais e administrativas, de acordo com a Lei no 10.028 de 2000. A sanção penal, nos termos da lei de crimes, recairá sobre aquele administrador público que não seguir as regras gerais da LRF, desde a elaboração das leis orçamentárias, até a publicação de todos os relatórios exigidos.

De acordo com Khair (2001), existem 11 situações de desrespeito à LRF que podem ser classificadas como transgressões fiscais e cerca de 64 situações que levam a punições penais, entre ações e omissões.

No Quadro 2 são apresentados alguns exemplos de transgressões à Lei de Responsabilidade Fiscal e suas sanções penais.

Outro aspecto destacado por Khair (2001) é o fato de que os crimes contra as finanças públicas não excluem o seu autor da reparação civil do dano causado ao patrimônio público. A punição criminal baseada na lei de crimes levará ainda o transgressor a responder por outros crimes associados. Considerando ainda que o Poder Legislativo e os tribunais de contas são os órgãos competentes para a fiscalização das contas da administração pública, no que tange ao cumprimento da LRF, não há dúvidas de que cresce a importância e o poder desses órgãos com o advento da lei.

\section{O controle interno e externo e a}

\section{Lei de Responsabilidade Fiscal}

Todos os órgãos públicos são obrigados a prestar contas à sociedade. Estas prestações de contas são sintetizadas em demonstrativos contábeis, como os balanços patrimoniais, financeiros e orçamentários. Na relação de agência, o cidadão (principal) deve fiscalizar o gestor dos recursos públicos, que são seus por natureza.

No entanto, as incapacidades técnica e operacional impedem que cada cidadão se ocupe na investigação permanente das prestações de contas dos responsáveis pelos recursos públicos. Nessas circunstâncias é que se faz necessária a existência de órgãos especializados para a verificação e análise da prestação de contas desses gestores que, em nome do cidadão, analisam e decidem sobre a regularidade ou não das despesas realizadas em serviços e obras públicas com o dinheiro arrecadado por meio de impostos. 
Quadro 1: Principais aspectos da Lei Complementar $n^{\circ} 101 / 2000$ para a gestão correta dos recursos públicos

\begin{tabular}{|c|c|c|}
\hline Aspectos a observar & Descrição & Norma legal \\
\hline $\begin{array}{l}\text { Cumprimento de } \\
\text { metas }\end{array}$ & $\begin{array}{l}\text { Obrigatoriedade para que União, Estados e } \\
\text { Municípios definam metas fiscais e assumam } \\
\text { compromissos públicos explícitos de desem- } \\
\text { penho fiscal nas suas respectivas leis orça- } \\
\text { mentárias, bem como as providências a se- } \\
\text { rem tomadas nos casos em que se verifique } \\
\text { descumprimento das normas ou desvios } \\
\text { injustificados e reiterados em relação aos } \\
\text { objetivos e metas da política fiscal. }\end{array}$ & $\begin{array}{l}\text { Capítulo II, } \\
\text { Art. } 4^{\circ}-10 \\
\text { da LRF. }\end{array}$ \\
\hline $\begin{array}{l}\text { Despesas com } \\
\text { pessoal }\end{array}$ & $\begin{array}{l}\text { Limites para despesas com pessoal. São de- } \\
\text { finidos na lei os limites de gastos com pes- } \\
\text { soal, com percentual das receitas, para os três } \\
\text { poderes da União, dos Estados, do Distrito } \\
\text { Federal e dos Municípios. Proibição de au- } \\
\text { mento de despesa com pessoal nos } 180 \text { dias } \\
\text { anteriores ao final do mandato do titular de } \\
\text { poder ou órgão. }\end{array}$ & $\begin{array}{l}\text { Capítulo IV, } \\
\text { seção II, Art. } \\
18 \text { - } 23 \text { da LRF. }\end{array}$ \\
\hline $\begin{array}{l}\text { Controle da dívida } \\
\text { pública }\end{array}$ & $\begin{array}{l}\text { Disciplina na realização de operações de cré- } \\
\text { dito dos diversos entes da Federação. } \\
\text { Conceituação e caracterização da dívida pú- } \\
\text { blica, de acordo com sua origem e natureza, } \\
\text { bem como as exigências estritas para seu re- } \\
\text { gistro e controle. Controle rigoroso da dívi- } \\
\text { da mobiliária e a necessária transparência por } \\
\text { meio da prestação de informações à popula- } \\
\text { ção, previamente à respectiva oferta públi- } \\
\text { ca. Fica consignada a exigência para a emis- } \\
\text { são de títulos públicos, com ampla prestação } \\
\text { de informações sobre forma, critérios, siste- } \\
\text { ma de colocação e remuneração, assim como } \\
\text { do competente registro em sistema centrali- } \\
\text { zado de liquidação e custódia. Concessão de } \\
\text { garantias por parte do setor público que con- } \\
\text { corre decisivamente para a disciplina fiscal. } \\
\text { Proibição de realização de operação de cré- } \\
\text { dito por antecipação de receita orçamentá- } \\
\text { ria no último ano de mandato. }\end{array}$ & $\begin{array}{l}\text { Capítulo VII, } \\
\text { Art. } 29 \text { - } 31 \\
\text { da LRF. } \\
\text { Art. } 39 \text { - } 42 \\
\text { da LRF. }\end{array}$ \\
\hline Restos a pagar & $\begin{array}{l}\text { Proibição ao titular de poder ou órgão de } \\
\text { contrair obrigação de despesa, nos dois últi- } \\
\text { mos quadrimestres do seu mandato, que não } \\
\text { possa ser cumprida integralmente dentro dele } \\
\text { ou que tenha parcelas a serem pagas no exer- } \\
\text { cício seguinte sem que haja suficiente dis- } \\
\text { ponibilidade de caixa. }\end{array}$ & Art. 42 da LRF. \\
\hline
\end{tabular}




\begin{tabular}{|c|c|c|}
\hline $\begin{array}{l}\text { A responsabilidade } \\
\text { fiscal entre os entes } \\
\text { federados }\end{array}$ & $\begin{array}{l}\text { O relacionamento entre os entes da Fede- } \\
\text { ração no que tange à responsabilidade fis- } \\
\text { cal. Regras para as transferências voluntári- } \\
\text { as de recursos e concessão de créditos. A } \\
\text { proibição de concessão de qualquer emprés- } \\
\text { timo ou financiamento para pagamento de } \\
\text { despesa de pessoal, bem como a realização } \\
\text { de operação de crédito que tenha por obje- } \\
\text { tivo renovar, refinanciar ou postergar dívi- } \\
\text { da anteriormente contraída. }\end{array}$ & $\begin{array}{l}\text { Art. } 32 \text { - } 38 \\
\text { da LRF. }\end{array}$ \\
\hline $\begin{array}{l}\text { Preservação do } \\
\text { patrimônio público }\end{array}$ & $\begin{array}{l}\text { Veda a aplicação da receita de capital deri- } \\
\text { vada da alienação de bens e direitos que } \\
\text { integram o patrimônio público para o finan- } \\
\text { ciamento de despesa corrente, salvo se desti- } \\
\text { nada por lei ao regime de previdência social, } \\
\text { geral e próprio dos servidores públicos. }\end{array}$ & Art. 44 da LRF. \\
\hline $\begin{array}{l}\text { Regras para a transfe- } \\
\text { rência de recursos } \\
\text { públicos para o setor } \\
\text { privado }\end{array}$ & $\begin{array}{l}\text { Disciplina e restrições às transferências de } \\
\text { recursos públicos para o setor privado, em } \\
\text { especial sob a forma de capitalizações, sub- } \\
\text { venções econômicas e subsídios de preços } \\
\text { públicos. A destinação e a utilização de re- } \\
\text { cursos públicos para pessoas físicas ou jurí- } \\
\text { dicas somente poderão ocorrer se vierem a } \\
\text { ser expressamente autorizadas em lei. }\end{array}$ & $\begin{array}{l}\text { Art. } 26 \text { - } 28 \\
\text { da LRF. }\end{array}$ \\
\hline $\begin{array}{l}\text { Fiscalização e trans- } \\
\text { parência }\end{array}$ & $\begin{array}{l}\text { Fiscalização da sociedade sobre os atos de } \\
\text { gestão pública. Divulgação e acesso amplo a } \\
\text { informações tempestivas, abrangentes, } \\
\text { consistentes e comparáveis sobre as contas } \\
\text { públicas dos três níveis de governo, incluindo } \\
\text { os objetivos e metas da política fiscal, as pro- } \\
\text { jeções que balizam os orçamentos públicos, } \\
\text { entre outros aspectos relevantes. Disponi- } \\
\text { bilização, em tempo real, de informações } \\
\text { pormenorizadas sobre a execução orçamen- } \\
\text { tária e financeira da União, dos Estados, do } \\
\text { Distrito Federal e dos Municípios. }\end{array}$ & $\begin{array}{l}\text { Art. } 48 \text { e } 49 \\
\text { da LRF. } \\
\text { Art. } 48-A, 73-A \text {, } \\
\text { 73-B e } 73-C \text { da } \\
\text { LC } 313 / 09 \text {. }\end{array}$ \\
\hline Responsabilização & $\begin{array}{l}\text { O descumprimento da LRF poderá ensejar } \\
\text { na aplicação de sanções institucionais e pe- } \\
\text { nalidades penais e administrativas. }\end{array}$ & $\begin{array}{l}\text { Art. } 25 \text { da LRF. } \\
\text { Lei 10.028/2000 }\end{array}$ \\
\hline
\end{tabular}

Fonte: Elaboração com base na LRF. 
Quadro 2: Principais penalidades aplicadas no descumprimento da Lei Complementar $\mathrm{n}^{\circ} 101 / 2000$

\begin{tabular}{|c|c|}
\hline Infração & Sanção/Penalidade \\
\hline $\begin{array}{l}\text { Ordenar, autorizar ou promover a realização de } \\
\text { operação de crédito, interno ou externo: } \\
\text { - sem prévia autorização legislativa; } \\
\text { - com inobservância de limite, condição ou montante } \\
\text { estabelecido em lei ou em resolução do Senado Federal; } \\
\text { - quando o montante da dívida consolidada ou despesa } \\
\text { relativa a pessoal ultrapassar os respectivos limites } \\
\text { máximos na forma da lei. }\end{array}$ & Reclusão de um a dois anos. \\
\hline $\begin{array}{l}\text { Ordenar ou autorizar a inscrição em restos a pagar de } \\
\text { despesa que não tenha sido previamente empenhada } \\
\text { ou que exceda o limite estabelecido na lei. }\end{array}$ & $\begin{array}{l}\text { Detenção de seis meses a dois } \\
\text { anos. }\end{array}$ \\
\hline $\begin{array}{l}\text { Ordenar ou autorizar a assunção de obrigação, nos dois } \\
\text { últimos quadrimestres do último ano do mandato ou } \\
\text { legislatura, cuja despesa não possa ser paga no mesmo } \\
\text { exercício financeiro ou, caso reste parcela a ser paga no } \\
\text { exercício seguinte, que não tenha contrapartida suficiente } \\
\text { de disponibilidade de caixa. }\end{array}$ & Reclusão de um a quatro anos. \\
\hline Ordenar despesa não autorizada por lei. & Reclusão de um a quatro anos. \\
\hline $\begin{array}{l}\text { Prestar garantia em operação de crédito sem que tenha } \\
\text { sido constituída contragarantia em valor igual ou superior } \\
\text { ao valor da garantia prestada, na forma da lei. }\end{array}$ & $\begin{array}{l}\text { Detenção de três meses a } \\
\text { um ano. }\end{array}$ \\
\hline $\begin{array}{l}\text { Deixar de ordenar, de autorizar ou de promover o cancela- } \\
\text { mento do montante de restos a pagar inscrito em valor } \\
\text { superior ao permitido em lei. }\end{array}$ & $\begin{array}{l}\text { Detenção de seis meses a } \\
\text { dois anos. }\end{array}$ \\
\hline $\begin{array}{l}\text { Ordenar, autorizar ou executar ato que acarrete aumento } \\
\text { de despesa total com pessoal, nos cento e oitenta dias ante- } \\
\text { riores ao final do mandato ou da legislatura. }\end{array}$ & Reclusão de um a quatro anos. \\
\hline $\begin{array}{l}\text { Ordenar, autorizar ou promover a oferta pública ou a } \\
\text { colocação no mercado financeiro de títulos da dívida } \\
\text { pública sem que tenham sido criados por lei ou sem que } \\
\text { estejam registrados em sistema centralizado de liquidação } \\
\text { e de custódia. }\end{array}$ & Reclusão de um a quatro anos. \\
\hline $\begin{array}{l}\text { Deixar de apresentar e publicar o Relatório de Gestão } \\
\text { Fiscal no prazo e com o detalhamento previsto na lei. }\end{array}$ & $\begin{array}{l}\text { Multa de } 30 \% \text { dos vencimen- } \\
\text { tos anuais que lhe der causa, } \\
\text { sendo o pagamento da multa } \\
\text { sua responsabilidade pessoal. }\end{array}$ \\
\hline
\end{tabular}

Fonte: Elaboração com base na Lei Complementar n 101/2000 e Lei Federal n 10.028/2000. 
A fiscalização da gestão fiscal, quanto ao cumprimento das normas da LRF, será exercida pelo Poder Legislativo, diretamente ou com o auxílio dos tribunais de contas, e pelo sistema de controle interno de cada poder e do Ministério Público. É o que estabelece o Art. 59 da lei:

Art. 59. O Poder Legislativo, diretamente ou com o auxílio dos Tribunais de Contas, e o sistema de controle interno de cada Poder e do Ministério Público, fiscalizarão o cumprimento das normas desta Lei Complementar.

Somando-se a isso a LRF fixou os prazos para que os tribunais de contas emitam parecer prévio conclusivo sobre as contas da gestão fiscal. Esses prazos estão estabelecidos no caput e no $\$ 1^{\circ}$ do Art. 57 da lei, que assim dispõe:

Art. 57. Os Tribunais de Contas emitirão parecer prévio conclusivo sobre as contas no prazo de sessenta dias do recebimento, se outro não estiver estabelecido nas constituições estaduais ou nas leis orgânicas municipais.

$\int 1^{\circ}$ No caso de Municípios que não sejam capitais e que tenham menos de duzentos mil habitantes o prazo será de cento e oitenta dias.

No âmbito do Tribunal de Contas do Estado do Rio Grande do Sul (TCE/RS), a fiscalização do cumprimento da LRF está descrita em diversas resoluções e instruções normativas, editadas a partir da LRF, sempre fundamentadas nas competências que lhe são conferidas pela Constituição Federal, Constituição Estadual e Lei Estadual no 11.424/2000, definida como a Lei Orgânica do Tribunal de Contas do Estado do Rio Grande do Sul.
O primeiro ato normativo expedido pelo TCE/RS, tratando sobre procedimentos a serem adotados com vistas à verificação do atendimento da LRF pelos prefeitos e presidentes de câmaras municipais, foi a Resolução TCE/RS no 553/2000. Essa Resolução em seu Artigo $1^{\circ}$ expressa:

Art. $1^{\circ}$ A presente Resolução objetiva regular a atividade de fiscalização do Tribunal de Contas do Estado, relativamente à observância da Lei Complementar Federal no 101, de 05 de maio de 2000 (Lei de Responsabilidade Fiscal).

$\mathrm{Na}$ mesma esfera, a referida Resolução alterou dispositivos do Regimento Interno do TCE/RS, merecendo destaque alguns incisos dos Artigos 11 e 12, que enumeram algumas atribuições desse tribunal:

Artigo 11 (...)

XXXIV - emitir Parecer sobre a Gestão Fiscal, no âmbito estadual, das autoridades referidas no artigo $56 \mathrm{da}$ Lei Complementar Federal no 101, de 05 de maio de 2000, à exceção das contas de gestão fiscal do Presidente do Tribunal de Contas.

Artigo 12 - Compete às Câmaras: (...) XI - emitir Parecer sobre as contas da Gestão Fiscal prestadas pelos Prefeitos Municipais, relativamente aos poderes Executivo e Legislativo.

Posteriormente, o TCE/RS expediu vários outros atos normativos, também tratando sobre procedimentos com vistas à verificação do atendimento da LRF, entre os quais se destacam as Resoluções no $586 /$ 2001 e 766/2007 e as Instruções Normativas $\mathrm{n}^{\circ} 12 / 2000$ e $19 / 2006$. 


\section{Aspectos avaliados pelo Tribunal de Contas para a emissão do parecer da gestão fiscal}

O Tribunal de Contas do Estado do Rio Grande do Sul estabeleceu por meio de atos normativos, como os mencionados anteriormente, e especialmente pelas Resoluções n $n^{\circ}$ 722/2005 e 766/2007, com as alterações introduzidas pela Resolução $\mathrm{n}^{\circ} 836 / 2008$, os procedimentos com a finalidade de fiscalizar e verificar no âmbito municipal.

Os dispositivos legais analisados pelo TCE/RS, que resultam na emissão do parecer pelo atendimento ou não atendimento da Lei Complementar $n^{\circ} 101$, de 2000, são apresentados no Quadro 3.

Conforme o Quadro 3, os dispositivos da LRF analisados pelo Tribunal de Contas do Estado do Rio Grande do Sul na emissão do parecer são: entrega dos relatórios de gestão fiscal no TCE, publicação e publicidade, controle interno, despesa com pessoal, equilíbrio das contas públicas, restos a pagar, endividamento, operações de crédito. Destaca-se a importância da ação do Tribunal de Contas, tanto na imposição quanto na cobrança dos procedimentos a serem adotados pela administração pública, decorrentes do advento da LRF, para a efetiva implementação e cumprimento dessa norma.

\section{Procedimentos metodológicos}

Este estudo caracteriza-se como descritivo e exploratório. Para Gil (2002, p. 42) a pesquisa descritiva "tem como objetivo primordial a descrição das características de determinada população ou fenômeno ou, então, o estabelecimento de relações entre variáveis". De outro modo,

Quadro 3: Dispositivos da LRF analisados pelo Tribunal de Contas do Estado do Rio Grande do Sul na emissão do parecer

\begin{tabular}{|c|c|}
\hline Procedimentos/Limites a observar & Norma legal \\
\hline $\begin{array}{l}\text { Entrega dos relatórios de } \\
\text { gestão fiscal no TCE }\end{array}$ & $\begin{array}{l}\text { Art. } 54 \text { e } 55 \text { da LRF, inciso I do Art. } 5^{\circ} \text { da LF } \\
\text { no }^{\circ} 10.028 / 2000, \text { Art. } 4^{\circ} \text {, inciso I ou II da Reso- } \\
\text { lução TCE/RS n } 695 / 2004\end{array}$ \\
\hline Publicação e publicidade & $\begin{array}{l}\int 2^{\circ} \text { do Art. } 55 \text { da LRF, inciso I do Art. } 5^{\circ} \text { da } \\
\text { LF n } n^{\circ} 10.028 / 2000 \text {, Decisões dos Processos } \\
\text { TCE } / \text { RS n }{ }^{\circ} 5017-0200 / 03-1 \text { (22-04-2004) e } \\
7648-0200 / 07 \text { (16-04-2008) }\end{array}$ \\
\hline Controle interno & Art. 54, parágrafo único da LRF \\
\hline Despesa com pessoal & $\begin{array}{l}\text { Art. 20, inciso III, alínea "a" (Executivo), "b" } \\
\text { (Legislativo) e Art. } 23 \text { da LRF }\end{array}$ \\
\hline Equilíbrio das contas públicas & Art. $1^{\circ}, \S 1^{\circ}$ da LRF \\
\hline Restos a pagar & Art. 42 da LRF \\
\hline Endividamento & $\begin{array}{l}\text { Inciso II do Art. } 3^{\circ} \text { da Resolução no 43/2001 } \\
\text { do Senado Federal }\end{array}$ \\
\hline Operações de crédito & $\begin{array}{l}\text { Inciso I do Art. } 7^{\circ} \text { e Art. } 10 \text { da Resolução } \\
\text { n }^{\circ} 43 / 2001 \text { do Senado Federal }\end{array}$ \\
\hline
\end{tabular}

Fonte: Elaboração com base na LRF e normas do TCE/RS. 
o estudo exploratório tem como uma de suas características o aprofundamento de conceitos preliminares sobre determinada temática não contemplada de modo satisfatório anteriormente (RAUPP; BEUREN, 2006, p. 80).

O estudo foi realizado por meio de pesquisa documental. Gil (2002) destaca que a pesquisa documental utiliza materiais ainda não analisados ou que ainda poderão ser reelaborados. Quanto à abordagem do problema, a pesquisa caracteriza-se como qualitativa. Raupp e Beuren (2006, p. 92) descrevem que "na pesquisa qualitativa concebem-se análises mais profundas em relação ao fenômeno que está sendo estudado".

A pesquisa foi realizada por meio da extração de dados publicados na página eletrônica do Tribunal de Contas do Estado do Rio Grande do Sul.

Diante do objetivo do estudo, observou-se se os princípios constitucionais e administrativos introduzidos pela LRF foram observados pelos municípios. Buscou-se analisar as decisões do TCE/ RS sobre a prestação de contas da gestão fiscal de todos os municípios do Estado, os itens analisados e os principais motivos que levaram à emissão do parecer favorável ou contrário à aprovação das contas.

A população e amostra do estudo foram todos os municípios do Estado do Rio Grande do Sul. O período analisado corresponde ao período de 2000 a 2008. Cabe salientar que o Estado do Rio Grande do Sul possuía no ano 2000467 municípios, número este que foi acrescido de 30 municípios que iniciaram suas atividades em 2001. Todavia, em dezembro de 2003, por determinação judicial, o Município de Pinto Bandeira teve suas atividades suspensas, sendo reintegrado ao município-mãe, Bento Gonçalves. Dessa forma, nos exercícios de
2001 e 2002 a população e amostra foram de 497 municípios, enquanto que, a partir de 2003, a população e amostra reduziram para 496 municípios.

A coleta e tratamento dos dados tomam como variável o tipo de decisão tomada pelo TCE/RS em relação à prestação de contas da gestão fiscal dos municípios do Estado no período de nove anos, incluindo o Poder Executivo e Legislativo.

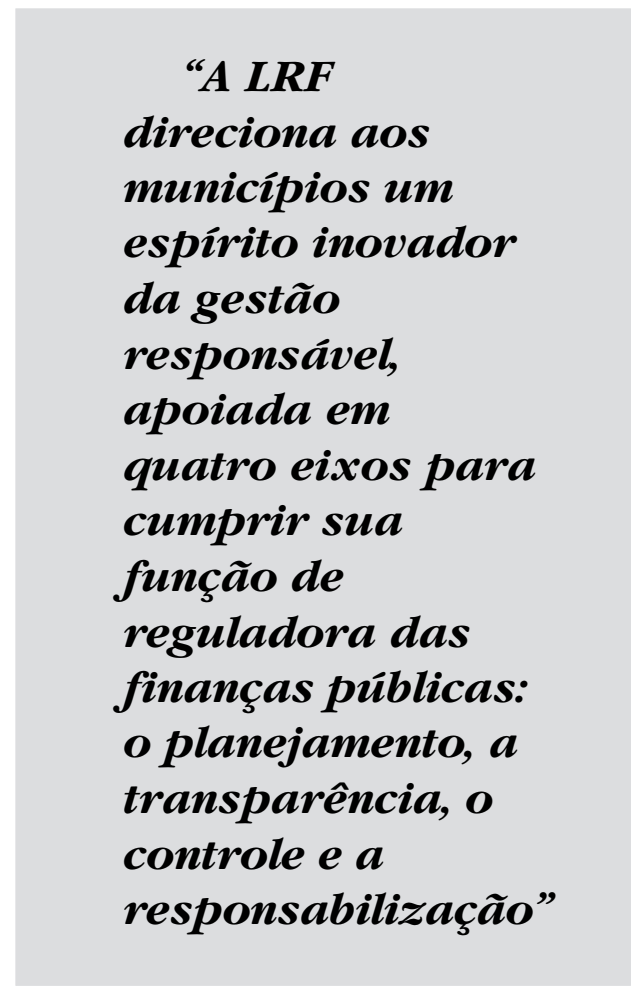

A base de dados utilizada para este trabalho são os pareceres do TCE/RS encontrados no site oficial do tribunal, referentes aos exercícios de 2000 a 2008, os quais relatam o tipo de manifestação do tribunal quanto à gestão fiscal. O estudo se limitou a comparar anualmente as decisões do TCE/RS no período analisado. 


\section{Análise e interpretação dos dados}

Neste capítulo são demonstrados inicialmente os resultados dos pareceres do TCE/RS, no período analisado, para o Poder Executivo e Legislativo dos municípios gaúchos. Posteriormente são descritos os fatores que fundamentaram a emissão dos pareceres.

\section{Decisões do Tribunal de Contas}

Para a análise e emissão dos pareceres das contas de gestão fiscal, o TCE/RS teve por base os dados fornecidos pelo Poder Executivo e Legislativo dos municípios, constituídos pelos demonstrativos da receita corrente líquida, da despesa com pessoal, dos restos a pagar, das disponibilidades de caixa, das operações de crédito, da dívida consolidada, das garantias e contragarantias, das despesas com folha de pagamento, do relatório da manifestação do controle interno e a sua efetiva atuação, além de serem verificados os prazos de entrega e de publicação dos relatórios.

Observou-se que os demonstrativos referidos são gerados automaticamente pelo Programa Autenticador de Dados (PAD), a partir da extração de dados da contabilidade dos próprios municípios, por meio do Sistema de Informações para Auditoria e Prestação de Contas (SIAPC) do TCE/RS.

Nesta seção são apresentadas as decisões do Tribunal de Contas do Estado do Rio Grande do Sul quanto às contas de gestão fiscal dos gestores.

$\mathrm{Na}$ Tabela 01 são demonstradas as decisões do TCE/RS do Poder Executivo dos municípios.

Por meio da Tabela 1, são identificadas as oscilações acentuadas nas decisões de atendimento e não atendimento à LRF. A decisão pelo não atendimento à lei aumenta nos exercícios de 2000, 2004, 2006 e 2008. Destes exercícios, é relevante destacar que 2000 compreende o ano em que entrou em vigor a lei, e que nos exercícios de 2002, 2004 e 2008 houve eleições municipais e término de mandato. Percebe-se também que, nos exercícios de final de mandato, ocorre uma variação cíclica e ascendente na porcentagem dos pareceres pelo não atendimento, o que pode representar uma diminuição dos níveis de preocupação dos gestores diante da reprovação de suas contas no último ano de seus mandatos.

Verifica-se que nos exercícios de 2001, 2003 e 2007 o índice de aprovação das

Tabela 1: Tipo de decisão do TCE dos poderes executivos municipais por ano

\begin{tabular}{lccccc}
\hline \multirow{2}{*}{ Ano } & Peloatendimento & LRF & \multicolumn{2}{c}{ Pelo não atendimento à LRF } & Total \\
\cline { 2 - 6 } & Quant. & $\mathbf{\%}$ & Quant. & \% & \\
\hline 2000 & 326 & 69,81 & 141 & 30,19 & 467 \\
\hline 2001 & 453 & 91,15 & 44 & 8,85 & 497 \\
\hline 2002 & 431 & 86,72 & 66 & 13,28 & 497 \\
\hline 2003 & 473 & 95,36 & 23 & 4,64 & 496 \\
\hline 2004 & 401 & 80,85 & 95 & 19,15 & 496 \\
\hline 2005 & 421 & 84,88 & 75 & 15,12 & 496 \\
\hline 2006 & 394 & 79,44 & 102 & 20,56 & 496 \\
\hline 2007 & 461 & 92,94 & 35 & 7,06 & 496 \\
\hline 2008 & 409 & 82,46 & 87 & 17,54 & 496 \\
\hline
\end{tabular}

Fonte: Dados da pesquisa. 
contas na gestão fiscal foi superior a 90\% dos municípios. Por outro lado, percebe-se que não há um crescimento contínuo do índice de aprovação das contas pelo TCE/ RS em todo o período analisado. Nesse aspecto chama a atenção principalmente o exercício de 2006, em que houve uma queda relevante nos pareceres pela aprovação das contas desde a entrada em vigor da lei.

Infere-se ainda que no exercício de 2000, ano da entrada em vigor da lei, $30,19 \%$ dos poderes executivos municipais não atenderam às normas da LFR, enquanto que em 2008 essa situação foi constatada em apenas $17,54 \%$. Isso direciona para um impacto da LRF na boa governança e para o aumento da aprovação das contas públicas municipais.

$\mathrm{Na}$ Tabela 2, apresentam-se as decisões do TCE/RS referentes às contas do Poder Legislativo dos municípios no período de 2000 a 2008.

Identifica-se na Tabela 2 que, no período analisado, houve um crescimento dos pareceres pelo atendimento da LRF nos legislativos municipais, representando 64,03\% em 2000 e 99,19\% em 2008. Somente no exercício de 2001, houve uma queda no percentual de atendimento da lei; a partir desse exercício, o crescimento foi constante e se acentuou principalmente a partir do exercício de 2003.

Destaca-se que diferentemente dos poderes executivos municipais, em que os mandatos são de quatro anos, nos poderes legislativos municipais os mandatos dos presidentes das câmaras, na maioria dos municípios, compreendem a um exercício. Conclui-se com isso que, mesmo nos exercícios onde houve término de mandato dos presidentes do Legislativo, o índice de aprovação das contas manteve-se elevado.

Infere-se que a LRF causou impacto na aprovação das contas dos poderes legislativos municipais, pois em 2000, ano da entrada em vigor da lei, 168 câmaras municipais receberam parecer pelo não atendimento da lei, caindo em 2008 para somente quatro câmaras.

\section{Análise descritiva dos aspectos avaliados para a decisão do Tribunal de Contas}

De acordo com os dados divulgados pelo TCE/RS, apresenta-se nesta seção uma síntese das avaliações efetuadas nas contas da gestão fiscal dos exercícios de 2002 a 2008. Esta análise ficou prejudicada nos exercícios de 2000 e 2001, pela não disponibilização dos dados pelo TCE/RS.

Tabela 2: Tipo de decisão do TCE dos poderes legislativos municipais por ano

\begin{tabular}{lccccc}
\hline \multirow{2}{*}{ Ano } & \multicolumn{2}{c}{ Pelo atendimento à LRF } & \multicolumn{2}{c}{ Pelo não atendimento à LRF } & Total \\
\cline { 2 - 6 } & Quant. & \% & Quant. & \% & \\
\hline 2000 & 299 & 64,03 & 168 & 35,17 & 467 \\
\hline 2001 & 292 & 58,75 & 205 & 41,25 & 497 \\
\hline 2002 & 387 & 77,87 & 110 & 22,13 & 497 \\
\hline 2003 & 486 & 97,98 & 10 & 2,02 & 496 \\
\hline 2004 & 469 & 94,56 & 27 & 5,44 & 496 \\
\hline 2005 & 473 & 95,36 & 23 & 4,64 & 496 \\
\hline 2006 & 479 & 96,57 & 17 & 3,43 & 496 \\
\hline 2007 & 490 & 98,79 & 6 & 1,21 & 496 \\
\hline 2008 & 492 & 99,19 & 4 & 0,81 & 496 \\
\hline
\end{tabular}

Fonte: Dados da pesquisa. 
Identificou-se que no exercício de 2002, do universo de municípios fiscalizados, no que tange ao item despesa com pessoal dos executivos e legislativos, $98,59 \%$ estão atendendo ao limite legal determinado. Referente ao item dívida consolidada líquida, somente um município encontrava-se acima do limite fixado legalmente pela Resolução no 40/2001, do Senado Federal, enquadrando-se na regra de transição.

Os motivos que levaram à emissão do parecer pelo não atendimento da LRF no ano de 2002, totalizando 176 processos entre o poderes legislativos e executivos, foram de diversas ordens: a) ausência de sistema de controle interno; b) despesas realizadas nos dois últimos quadrimestres do último ano de mandato, sem a correspondente disponibilidade financeira; c) ausência de cumprimento do limite de gastos totais do Legislativo; d) despesa total com pessoal superior ao limite permitido; e) excesso ao limite de expansão na despesa total com pessoal.

No exercício de 2003, constatou-se que do universo de municípios fiscalizados, no que tange ao item despesa com pessoal, envolvendo executivos e legislativos, 98,79\% atenderam ao limite legal determinado. Quanto à dívida consolidada líquida, todos os municípios encontravamse dentro do limite fixado pela Resolução $n^{\circ}$ 40/2001, do Senado Federal.

Os motivos que levaram à emissão do parecer pelo não atendimento da LRF, totalizando 33 processos entre os poderes executivos e legislativos, foram de diversas ordens: a) ausência de sistema de controle interno; b) despesas realizadas nos dois últimos quadrimestres do último ano de mandato, sem a correspondente disponibilidade financeira; c) ausência de cumprimento do limite de gastos totais do
Legislativo; d) despesa total com pessoal superior ao limite permitido; e) excesso ao limite de expansão na despesa total com pessoal.

Partindo-se para o exercício de 2004, foram verificados que, dos municípios fiscalizados no que tange ao item despesa com pessoal, envolvendo os poderes executivos e legislativos, 98,59\% estão atendendo ao limite legal determinado. No que se refere ao item dívida consolidada líquida, todos os municípios encontravamse dentro do limite fixado pela Resolução $n^{\circ}$ 40/2001, do Senado Federal.

Os motivos que levaram à emissão do parecer pelo não atendimento da LRF, totalizando 122 processos entre o Poder Legislativo e Executivo, são de diversas ordens: a) ausência de sistema de controle interno; b) despesas realizadas nos dois últimos quadrimestres do último ano de mandato, sem a correspondente disponibilidade financeira; c) falta do equilíbrio financeiro (total dos restos a pagar superior às disponibilidades financeiras); d) ausência de cumprimento do limite de gastos totais do Legislativo; e) despesa total com pessoal superior ao limite permitido, em descumprimento à Lei de Responsabilidade Fiscal.

Em 2005, além do desequilíbrio financeiro, situação apresentada em 60 dos 75 poderes executivos municipais que receberam parecer pelo não atendimento $\mathrm{da}$ LRF, constatou-se, também, o excesso de despesa com pessoal, a entrega de relatórios fora do prazo, falta de publicação de relatórios e publicação de relatórios fora do prazo.

Com relação aos pareceres pelo não atendimento da LRF, recebidos por 23 legislativos municipais, foram motivados, principalmente, pelo desequilíbrio financeiro, restos a pagar, não publicação ou publicação de relatórios fora do prazo, 
descumprimento do limite de gastos totais e com folha de pagamento.

No exercício de 2006, além do desequilíbrio financeiro, situação apresentada em 87 dos 102 poderes executivos municipais que receberam parecer pelo não atendimento da LRF, a matéria de segunda maior incidência foi relacionada à publicação de relatórios de gestão fiscal e relatórios resumidos da execução orçamentária.

Quanto aos legislativos municipais, os 17 pareceres recebidos pelo não atendimento da LRF foram motivados, principalmente, pela publicação de relatórios de gestão fiscal, pelo desequilíbrio financeiro, restos a pagar e gastos com folha de pagamento.

No exercício de 2007, verificou-se que, além do desequilíbrio financeiro, situação apresentada em 23 dos 35 poderes executivos municipais que receberam parecer pelo não atendimento da LRF, a matéria de segunda maior incidência foi relacionada a não realização das audiências públicas em oito municípios.

A emissão dos pareceres pelo não atendimento da LRF, recebidos por seis legislativos municipais, foi motivada pela entrega fora do prazo do relatório de gestão fiscal e gasto com folha de pagamento acima do limite legal, ambos com duas ocorrências.

Em 2008, último exercício analisado, as matérias relacionadas aos restos a pagar e desequilíbrio financeiro foram as que apresentaram maior incidência nos pareceres pelo não atendimento da LRF pelos poderes executivos municipais.

Nos poderes legislativos municipais, os quatro pareceres recebidos pelo não atendimento da LRF foram motivados pelas entregas dos Relatórios de Validação e Encaminhamento (RVE), publicações de Relatórios de Gestão Fiscal (RGF), restos a pagar e desequilíbrio financeiro.
Dos dados apresentados, infere-se que a maioria dos municípios gaúchos está atendendo aos limites e condições estabelecidos pela Lei de Responsabilidade Fiscal.

\section{Conclusões}

O estudo objetivou analisar os impactos da Lei de Responsabilidade Fiscal na gestão das contas públicas dos municípios do Estado do Rio Grande do Sul.
“Os resultados da pesquisa demonstram que o impacto da LRF na gestão pública está exigindo uma nova postura dos gestores públicos, atribuindo a eles a responsabilidade de transformar a administração pública”
Para alcançar o objetivo foi realizada uma pesquisa descritiva, por meio de análise documental, considerando como documentos os dados publicados na página eletrônica do Tribunal de Contas do Estado do Rio Grande do Sul.

Os resultados da pesquisa demonstram que o impacto da LRF na gestão pública está exigindo uma nova postura dos 
gestores públicos, atribuindo a eles a responsabilidade de transformar a administração pública.

Denota-se que um dos fatores dessa nova postura dos gestores públicos, a partir da LRF, se deve à forte atuação do Tribunal de Contas do Estado no acompanhamento e controle do efetivo cumprimento da lei e na atribuição de responsabilidades e penalidades, para aqueles que não cumprem com suas obrigações.

A pesquisa apresentou resultados que demonstram os impactos da LRF no aumento da aprovação das contas das prefeituras gaúchas. Prova disso é que no exercício de 2000 , ano da entrada em vigor da lei, 30,19\% dos poderes executivos municipais não haviam atendido às normas da LRF, em 2008 esse percentual caiu para 17,54\%. Quanto aos poderes legislativos municipais, evidencia-se também o impacto no percentual de pareceres favoráveis, pois, em 2000, 36\% não haviam atendido às normas da LRF, enquanto que em 2008 esse percentual caiu para $1 \%$.

Outro fator que se destaca na pesquisa é o fato de que as contas dos poderes executivos municipais apresentam percentual maior de parecer pelo não atendimento da LRF nos anos de eleição municipal, que são os exercícios de encerramento de mandato, que ocorreram em
2000, 2004 e 2008. Essa situação não é verificada nos poderes legislativos, que, na maioria dos municípios, apresentam mandatos anuais dos seus presidentes.

Por outro lado, deve-se enfatizar que o caráter normatizador e sancionador da lei e as ações adotadas pelo Tribunal de Contas, no que se refere à cobrança e ao respeito por parte do gestor público às normas da Lei de Responsabilidade Fiscal, surtiram efeito. Tal fato pode ser comprovado no declínio dos pareceres pelo não atendimento das normas da LRF, emitidos nos últimos nove exercícios.

Conclui-se que, embora seja condição necessária, a lei isoladamente não é suficiente para garantir mudanças de postura e, consequentemente, a seriedade e responsabilidade no planejamento e acompanhamento da aplicação dos recursos. A pesquisa também apresentou conclusões que apontam para outras investigações. Assim, diante das limitações encontradas, recomenda-se a realização de pesquisa comparando os dados dos municípios do Estado do Rio Grande do Sul e dos diversos estados brasileiros. Recomenda-se também a comparação dos impactos da LRF nos resultados das contas dos governos estaduais.

(Artigo recebido em fevereiro de 2012. Versão final em maio de 2012).

\section{Referências}

Brasil. Constituição da República Federativa do Brasil de 1988. Brasília, 1988. Disponível em: <http://ww.planalto.gov.br>. Acesso em: 12 dez. 2009.

. Decreto-Lei no 2.848, de 7 de dezembro de 1940. Código Penal. Diário

Oficial da União, Rio de Janeiro, RJ, 31 dez. 1940. Disponível em: <http:// www6.senado.gov.br/ legislacao/ListaPublicacoes.action?id=102343>. Acesso em: 15 dez. 2009. 
. Lei $\mathrm{n}^{\circ}$ 1.079, de 10 de abril de 1950. Define os crimes de responsabilidade e regula o respectivo processo de julgamento. Diário Oficial da União, Rio de Janeiro, RJ, 12 abr. 1950. Disponível em: <http://www.planalto.gov.br/ccivil_03/leis/ L1079.htm>. Acesso em: 15 dez. 2009.

. Lei Complementar no 101, de 04 de maio de 2000. Estabelece normas de finanças públicas voltadas para a responsabilidade na gestão fiscal e dá outras providências. Diário Oficial da União, Brasília, DF, 5 maio 2000. Disponível em: <http:// www.planalto.gov.br>. Acesso em: 15 dez. 2009.

. Lei Federal no 10.028, de 19 de outubro de 2000. Altera o Decreto-Lei ${ }^{\circ}$ 2.848, de 7 de dezembro de 1940 - Código Penal, a Lei no 1.079, de 10 de abril de 1950, e o Decreto-Lei no 201, de 27 de fevereiro de 1967. Diário Oficial da União, Brasília, DF, 20 dez. 2000. Disponível em: <http://ww.planalto.gov.br>. Acesso em: 12 dez. 2009. Estado do Rio Grande do Sul. Lei no 11.424, de 06 de janeiro de 2000. Lei orgânica do Tribunal de Contas do Rio Grande do Sul. Disponível em: < http:/ / www.tce.rs.gov.br/ legislacao/lei_organica/index.php>. Acesso em: 15 dez. 2009.

Lopes, Eduardo Caíres Bestilleiro; SLOMSKI, Valmor. Responsabilidade Fiscal versus Responsabilidade Social: um estudo nos municípios paulistas premiados pelo programa de incentivo à gestão fiscal responsável implementado pelo Conselho Federal de Contabilidade. In: Congresso USP de Contabilidade e Controladoria, 01, 2004, São Paulo. Anais... São Paulo: USP, 2004. 1 CD-ROM.

GiL, Antonio Carlos. Como Elaborar Projetos de Pesquisa. 4. ed. São Paulo: Atlas, 2002.

KHAIR, Amir Antônio. Gestão fiscal responsável simples municipal: guia de orientação para prefeituras. Brasília: Ministério do Planejamento, Orçamento e Gestão; BNDES, 2001. Disponível em: <http://www.federativo.bndes.gov.br>. Acesso em: 06 mar. 2010.

Moura Neto, João S.; Palombo, Paulo Eduardo Modelo. Lei de Responsabilidade Fiscal, Transferências e a Arrecadação Própria dos Municípios Brasileiros. In: Encontro DA Associação Nacional de Pós-graduação e Pesquisa em Administração, 09, 2006, Salvador. Anais... Rio de Janeiro: ANPAD, 2006. 1 CD-ROM.

Nóbrega, Marcos. Lei de Responsabilidade Fiscal e leis Orçamentárias. São Paulo: Editora Juarez de Oliveira, 2002.

Nunes, Dejanira de Pinho Rebouças. Administração Pública e a Lei de Responsabilidade Fiscal. São Paulo: Atlas, 2002.

Oliveira, Regis Fernandes de. Responsabilidade fiscal. 2. ed. rev. São Paulo: Ed. Revista dos Tribunais, 2002.

Pereira, Jerônimo Rosário Tanan; Silva, Vandenir Albuquerque. Efeitos da Lei de Responsabilidade Fiscal sobre a prestação de contas em prefeituras baianas. In: Congresso USP de Contabilidade e Controladoria, 09, 2009, São Paulo. Anais... São Paulo: USP, 2009. 1 CD-ROM.

Raupp, Fabiano Maury; Beuren, Ilse Maria. Como Elaborar Trabalhos Monográficos em Contabilidade. 3. ed. São Paulo: Atlas, 2006.

Tribunal de Contas do Estado do Rio Grande do Sul (TCE/RS). Resolução no 553/ 2000. Dispõe sobre a fiscalização, no âmbito do Tribunal de Contas do Estado, do que 
estabelece a Lei Complementar Federal no 101, de 05 de maio de 2000, e altera o regimento Interno do Tribunal de Contas do Estado, bem como a Resolução no 414, de 05 de agosto de 1992. Disponível em: http:/ /www.tce.rs.gov.br/legislacao/resolucoes_e_ins/ pdf/ res_553_00.pdf. Acesso em: 15 dez. 2009.

Resolução no 544/2000. Aprova a consolidação e introduz alterações no Regimento Interno do Tribunal de Contas do Estado do Rio Grande do Sul. Disponível em: http://www.tce.rs.gov.br/legislacao/regimento_interno_2008.pdf. Acesso em: 15 dez. 2009.

. Resolução no 722/2005. Dispõe sobre a disponibilização dos Relatórios de Validação e Encaminhamento (RVE) e de Gestão Fiscal, no âmbito das entidades e órgãos da administração pública municipal direta e indireta, na página do Tribunal de Contas na Internet, visando à transparência da gestão fiscal, bem como das atualizações dos procedimentos a serem adotados pelo Tribunal de Contas do Estado para fiscalização no âmbito municipal, de que trata a Lei Complementar $n^{\circ} 101$, de 04 de maio de 2000. Disponível em: http://www.tce.rs.gov.br/LRF/municipal/legislacao/ Res_722_05.pdf. Acesso em: 15 dez. 2009.

. Resolução n n $^{586 / 2001}$. Dispõe sobre os procedimentos a serem adotados pelo Tribunal de Contas do Estado para fiscalização, em âmbito municipal, do que estabelece a Lei Complementar Federal no 101, de 05 de maio de 2000. Disponível em: http://www.tce.rs.gov.br/legislacao/resolucoes_e_ins/pdf/res_586_01.pdf. Acesso em: 15 dez. 2009.

. Resolução nº 766/2007. Dispõe sobre a entrega, envio e disponibilização dos dados e informações em meio informatizado, que os responsáveis pelos órgãos ou entidades da administração direta e indireta municipal, inclusive consórcios públicos, devem fazer a este Tribunal, de acordo com as competências estatuídas nos incisos I, II, III e IV do Art. 71 da Constituição Federal, adaptados ao Estado por força do Art. 71 da Constituição Estadual, e dá outras providências. Disponível em: http://www.tce.rs.gov.br/ sistemas_controle/SIAPC/pdf/Res_TCERS_n766_2007.pdf. Acesso em: 15 dez. 2009. . Resolução no 836/2008. Altera e acrescenta dispositivos na Resolução $n^{\circ}$ 765/2006. Disponível em: http://www.tce.rs.gov.br/legislacao/resolucoes_e_ins/pdf/ res_836_2008.pdf. Acesso em: 15 dez. 2009.

. Instrução Normativa $n^{\circ} 12 / 2000$. Dispõe sobre a regulamentação da Resolução TCE-RS no 553, de 06 de setembro de 2000. Disponível em: http:// www.tce.rs.gov.br/legislacao/resolucoes_e_ins/pdf/inst_norm_12_00.pdf. Acesso em: 15 dez. 2009.

. Instrução Normativa n $19 / 2006$. Dispõe sobre as normas e os procedimentos de remessa da Manifestação Conclusiva da Unidade de Controle Interno acerca do cumprimento das normas da Lei Federal Complementar $\mathrm{n}^{\circ} 101$, de 04 de maio de 2000, pelos Chefes dos Poderes Executivo e Legislativo Municipais. Disponível em: http://www.tce.rs.gov.br/legislacao/resolucoes_e_ins/pdf/in-19_MCI2006.pdf. Acesso em: 15 dez. 2009.

. Contas de Gestão Fiscal, Âmbito Municipal. Estatísticas Anuais das Contas de Gestão Fiscal. Disponível em: <http:/ /www.tce.rs.gov.br>. Acesso em: 15 dez. 2009. SAntos, Sandra Regina Toledo dos. O impacto da LRF na arrecadação tributária dos municípios Gaúchos: uma análise do período de 1996 a 2005. In: Congresso UsP De 
Contabilidade E Controladoria, 09, 2009, São Paulo. Anais... São Paulo: USP, 2009. 1 CD-ROM.

Silva. Eliane de Sousa. A LRF e a Necessidade de Transparência na Previsão e Realização da Renúncia de Receita no Estado da Babia. [200-] Disponível em: http://www.tce.ba.gov.br/ files/artigo_LRF.pdf. Acesso em: 16 fev. 2010. 


\section{Resumo - Resumen - Abstract}

O impacto da Lei de Responsabilidade Fiscal: uma análise do desempenho das contas públicas municipais do Estado do Rio Grande do Sul

Ari Söthe; Vilson Söthe e Clésia Ana Gubiani

A partir do ano de 2000, com a publicação da Lei Complementar no 101 (LRF), a gestão pública no Brasil sofreu alterações na sua conduta, especialmente em relação à postura dos gestores, exigindo maior responsabilidade sobre os gastos públicos. O estudo teve por objetivo analisar os impactos da Lei de Responsabilidade Fiscal nas contas públicas dos governos municipais do Estado do Rio Grande do Sul. Para isso, foi analisado até que ponto a LRF contribuiu para o aumento de aprovação de prestação de contas dos municípios do Estado do Rio Grande do Sul. Foi realizada uma pesquisa descritiva com abordagem qualitativa, por meio de análise dos aspectos avaliados e levados em consideração pelo Tribunal de Contas do Estado do Rio Grande do Sul (TCE/RS) para o julgamento das contas municipais. Os resultados da pesquisa denotam a influência positiva da LRF na gestão pública municipal, pois houve aumento de aprovação de prestação de contas dos poderes executivos e legislativos municipais por parte do TCE/RS. Os resultados evidenciam também que as contas dos poderes executivos municipais apresentam um percentual maior de parecer pelo não atendimento da LRF nos exercícios de encerramento de mandato.

Palavras-chave: Lei de Responsabilidade Fiscal contas públicas municipais, Estado do Rio Grande do Sul

El impacto de la Ley de Responsabilidad Fiscal: un análisis de la ejecución de cuentas públicas municipales del Estado de Rio Grande do Sul (Brasil)

Ari Söthe; Vilson Söthe y Clésia Ana Gubiani

Desde el año 2000 con la publicación de la Ley Complementaria no 101 (LRF), la gestión pública en Brasil ha experimentado cambios en su comportamiento, especialmente con respecto a la actitud de los directivos, exigiendo una mayor rendición de cuentas sobre el gasto público. El estudio tuvo como objetivo analizar los impactos de la Ley de Responsabilidad Fiscal en las cuentas públicas de los gobiernos municipales del Estado do Rio Grande do Sul. Para esto, se examinó la medida en que la LRF ha contribuido para una mayor adopción de la rendición de cuentas de los municipios del Estado dol Rio Grande do Sul. Se realizó una investigación descriptiva de enfoque cualitativo, a través del análisis de los aspectos evaluados y tenidos en cuenta por el Tribunal de Cuentas del Estado do Rio Grande do Sul (TCE/RS) para la adjudicación de las cuentas municipales. Los resultados de la búsqueda denotan la influencia positiva de la LRF en la administración pública municipal, ya que hubo un aumento en la adopción de la rendición de cuentas de los consejos ejecutivo y legislativo municipales por el TCE/RS. Los resultados también muestran que las cuentas de los poderes ejecutivos municipales tienen un mayor porcentaje de decisión por el incumplimiento de la LRF en los últimos años de su mandato.

Palabras clave: Ley de Responsabilidad Fiscal, cuentas públicas municipales, Estado do Rio Grande do Sul 
The impact of the Law Of Fiscal Responsibility: an analysis of the performance of the municipal public accounts of the State of Rio Grande do Sul

Ari Söthe; Vilson Söthe and Clésia Ana Gubiani

Starting from the year of 2000, with the publication of the Complementary Law no 101 (LRF), the public administration in Brasil suffered alterations in its conduct, especially in relation to the managers, demanding larger responsibility on the public expenses. The study has for objective to analyze the impacts of the Law of Fiscal Responsibility in the public accounts of municipalities of the State of Rio Grande do Sul. For that, it was analyzed to which extent the Law of Fiscal Responsibility-LRF - contributed to the increase of approval of accounts rendered by municipalities of the State of Rio Grande do Sul. Descriptive research was accomplished with qualitative approach, through analysis of the appraised aspects and taken into account by the Court of the State of Rio Grande do Sul (TCE/RS) for the adjudication of municipal accounts. The results of the research denote for the positive influence of LRF in the municipal public administration, because, there was an increase of approval of accounts rendered of the executive and legislative municipality, for the TCE/RS. The results also show, that the accounts of the municipal executive governance, present a percentile larger of seeming for the no service to LRF the exercises of closing years.

Keywords: Law of Fiscal Responsibility, municipal public accounts, State of Rio Grande do Sul

Ari Söthe

Mestre em Ciências Contábeis da Universidade Regional de Blumenau (FURB) Professor da Universidade Federal da Fronteira Sul (UFFS). Contato: ari.sothe@uffs.edu.br

Vilson Söthe

Especialista em Planejamento Tributário. Professor da FAI Faculdades de Itapiranga. Contato: vilsoethe@brturbo.com.br Clésia Ana Gubiani

Mestre em Ciências Contábeis da Universidade Regional de Blumenau (FURB). Professora da Universidade Comunitária da Região de Chapecó (Unochapecó). Contato: clesiapzo@yahoo.com.br 